\title{
Thyroid dysfunction among Greek type 1 and type 2 diabetic patients attending an outpatient clinic
}

\author{
Maria E. Barmpari, Maria Kokkorou, Anastasia Micheli, Irene Alexiou, Elefteria Spanou, Marina Noutsou, Anastasia \\ Thanopoulou
}

Diabetes Clinic,2 ${ }^{\text {nd }}$ Department of Internal Medicine, Hippokratio General Hospital of Athens, Athens Medical School, Greece

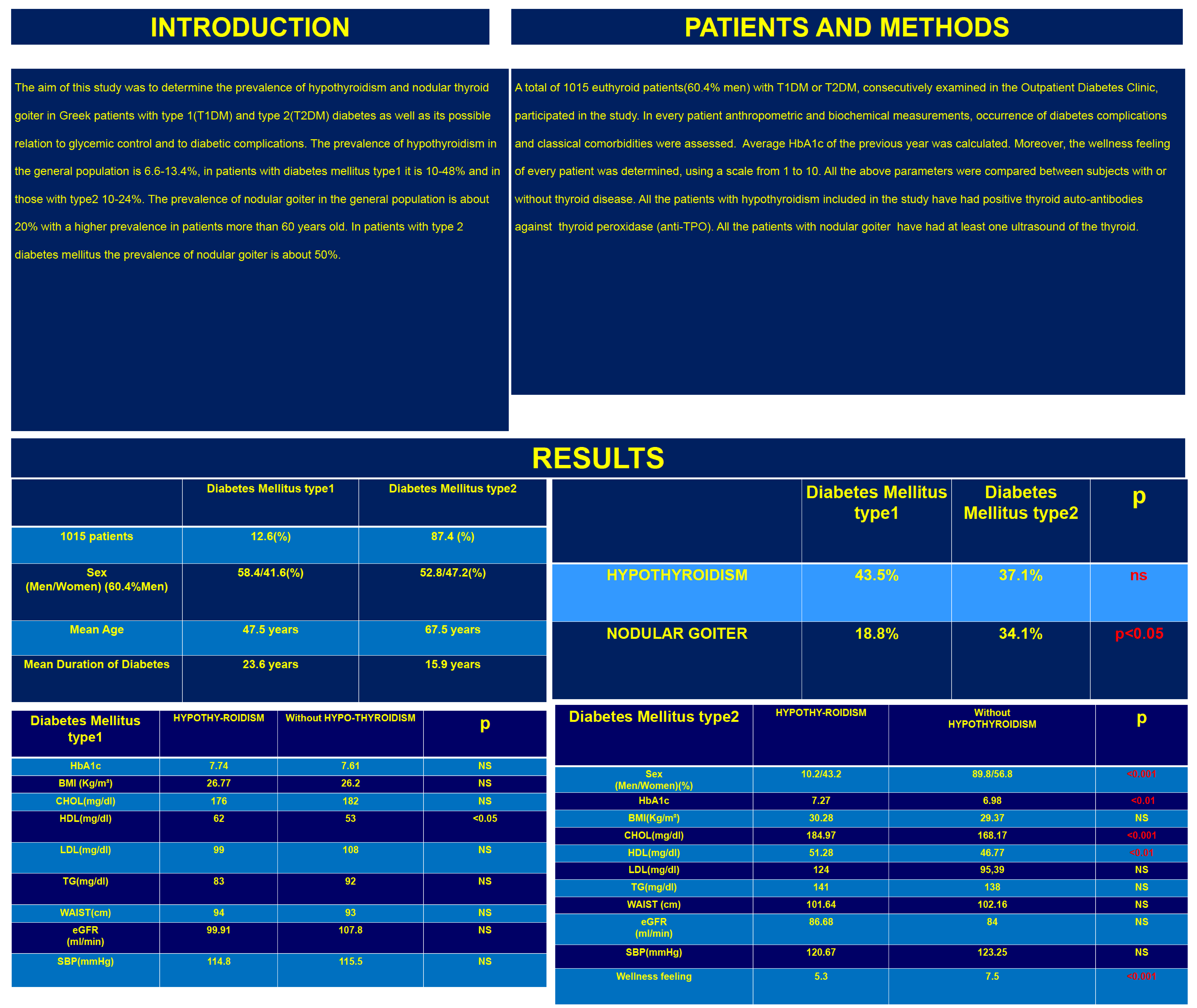

In both types of diabetes mellitus, there were no statistically significant differences between the patients with and without nodular goiter. Additionally, no statistically significant differences concerning the occurrence of diabetes complications and classical comorbidities, were found between patients with and without hypothyroidism and those with and without nodular goiter.

\section{CONCLUSIONS}

Screening for thyroid disease among patients with type 2 diabetes should be routinely considered because of the high prevalence of hypothyroidism and nodular goiter in these patients. It is another risk factor that if remains undiagnosed could aggravate the usual comorbidities of diabetes mellitus. 